\title{
Exclusive Breastfeeding, Blood Volume and Bleeding Duration on Postpartum Period at Kassi-Kassi Primary Health Centre (PHC), Makassar, Indonesia
}

\author{
Sundari $^{1}$, Sitti Patimah ${ }^{2}$, A. Reski Amelia ${ }^{2}$, M. Akbar Alwi ${ }^{3}$, Lina Fitriani ${ }^{4}$, Daswati ${ }^{5}$, Sumiaty $^{6}$ \\ ${ }^{1}$ Assistant Professor, Department of Midwifery, Muslim Indonesia of University, Makassar, Indonesia, ${ }^{2}$ Assistant \\ Professor, Department of Nutrition, Muslim Indonesia of University, Makassar, Indonesia, ${ }^{3}$ Assistant Professor, \\ Health Faculty, Patria Artha University, Makassar, Indonesia, ${ }^{4}$ Assistant Professor, Department of Midwifery, \\ BIGES College of Health Science, Polman, Indonesia, ${ }^{5}$ Assistant Professor, Department of Midwifery, \\ Muhammadiyah University, Makassar, Indonesia, ${ }^{6}$ Assistant Professor, Department of Midwifery, Polytechnic of \\ Health, Ministry of Health, Palu, Indonesia
}

\begin{abstract}
Introduction: Breastfeeding has been widely recognised as benefiting for infants and mothers. It could avoid haemorrhage after giving birth (postpartum). The study aimed to observe the association between exclusive breastfeeding, blood volume and blood duration in a postpartum period.

Method: This was an analytic study with a cross-sectional design. The number of samples was 56 postpartum women who were chosen by purposive sampling method. A questionnaire was used in collecting data by interviewing the respondents. Data was analysed using descriptive statistic and chi-square test.

Result: There were $78.57 \%$ respondents breastfed exclusively and $21.43 \%$ did not breastfeed exclusively. In this study, exclusive breastfeeding related to bleeding duration $(\mathrm{p}=0.00)$, while blood volume was not associated with exclusive breastfeeding $(\mathrm{p}=0.06)$.

Conclusion: There was a relationship between exclusive breastfeeding and blood duration. Meanwhile, exclusive breastfeeding was not associated with blood volume.
\end{abstract}

Keywords: Exclusive Breastfeeding, Blood Volume and Bleeding Duration.

\section{Introduction}

Providing exclusive breastfeeding is an important intervention to reduce neonatal, infant or child morbidity and mortality. It is a good strategy as well for child survival. Breast milk is a very good intake in the first thousand days of birth because it provides complete nutrition for baby and it is ideal for the few first months

\section{Corresponding Author:}

\section{Akbar Alwi}

Health Faculty, Patria Artha University, Makassar, Indonesia

e-mail: akbaralwi@patria-artha.ac.id as it is nurture provided by the nature ${ }^{1}$. Breastfeeding infants is the best way to improve nutrition and the quality of human resources.

Breastfeeding optimizes the development of nerves and the brain, provides immune substances against disease and builds the emotional bond between mother and baby ${ }^{2}$. Breastfeeding not only give benefits for baby but also for mother. Early initiation of breastfeeding could reduce the risk of postpartum haemorrhage ${ }^{3}$.

Postpartum Haemorrhage (PPH) is a major determinant in maternal morbidity and mortality ${ }^{4,5}$. The consequence of excessive blood loss during childbirth is a significant problem. According to World Health Organization (WHO) in ${ }^{3}$, it is estimated that around 
800 women die every day because of preventable disease during pregnancy and postpartum, in which 99\% of the death are indeveloping countries. Among ASEAN countries, Indonesia is on the fifth in terms of maternal death. The main cause of the deaths is complications during pregnancy and mostly occur during the postpartum period which was mainly caused by haemorrhage ${ }^{6}$. WHO defines PPH as a blood loss of $500 \mathrm{ml}$ or more, while severe PPH is defined as vaginal bleeding more than $1000 \mathrm{ml}$ within 24 hours after birth ${ }^{7}$. By this definition, around 14 million cases of postpartum haemorrhage (PPH) occur each year ${ }^{4}$, affecting about $6 \%$ of all women giving birth around the world ${ }^{8}$. There was some research about PPH in Indonesia have been carried out. However, this study focused on exclusive breastfeeding, related to blood volume and duration of bleeding after birth.

\section{Method}

This study is an observational study with crosssectional design which was conducted in Kassi-Kassi Primary Health Centre (PHC) area, Makassar, Indonesia. This study focused on exclusive breastfeeding at one month of postpartum period. Sampling method used was purposive and the number of samples was 56 . The criteria of sample:

Inclusive criteria: women who have a baby aged 1 month and live in Kassi-Kassi PHC area, the women breastfed exclusively (breast milk only) and did not havehealth problems related to their labour.

Exclusive criteria: women did not breastfeed exclusively and have health problems during the postpartum period.

For data collection, a questionnaire was used as a research instrument. The questionnaire was consisted of some questions such as characteristic of respondents, parity, type of labour, sanitary pad change and duration of bleeding. Respondents were interviewed directly when visiting PHC for their baby's immunization. Data were analysed by using SPSS program and the result was showed in frequency and cross-tabulation table. Chi-square test was applied to observe the association between exclusive breastfeeding, blood volume and duration of vaginal bleeding.
Findings: The number of samples which was analysed in this research is 56 . Table 1 shows that of 56 respondents, most of them aged $20-35$ years $(89.29 \%)$ and only $3.57 \%$ aged under 20 years. The highest education level isuniversity, $53.57 \%$ respondents who graduated from university and $7.14 \%$ was junior high school. In this study, most of the women were housewife (60.71\%) and a civil servant (7.14\%).

The percentage of respondents who are parity 1 and 2 is $57.14 \%$ and 42.86 respectively. For the delivery process, the vast majority of respondents gave birth through vaginal birth (96.43\%) and caesarean only $3.57 \%$.

In terms of breastfeeding, $78.57 \%$ breastfed exclusively and $21.43 \%$ non-exclusive. Most of the women $(96.43 \%$ ) have blood volume loss $<500 \mathrm{ml}$ and only $3.57 \%$ more than $500 \mathrm{ml}$. For the duration of vaginal bleeding, less than 14 days (78.57\%) and $21.43 \%$ more than 14 days.

Table 2 and 3 show the association between exclusive breastfeeding, blood volume and duration of vaginal bleeding. All respondents (100\%) who breastfed exclusively have blood volume $<500 \mathrm{ml}$ (table 2 ). However, the percentage of women who did not breastfeed exclusively and had blood volume $<500 \mathrm{ml}$ was high as well $(83.3 \%)$. Respondents who did not breastfeed exclusively and had blood volume $>500 \mathrm{ml}$ was $16.7 \%$. Chi-square test revealed that there was no association between exclusive breastfeeding and blood volume $(\mathrm{p}=0,06)$.

Table 3 shows that $97.7 \%$ of respondents who breastfed exclusively and the duration of vaginal bleeding was under 14 days. Meanwhile, respondents who did not breastfeed exclusively and had bleeding duration $>14$ days were $91.7 \%$. The percentage of women who did not breastfeed exclusively and had bleeding duration $<$ 14 days was $8.3 \%$ and mother who breastfed exclusively but had bleeding duration $>14$ days was $2.3 \%$. Chisquare test show that exclusive breastfeeding related to the duration of vaginal bleeding $(p=0.00)$. These results can be observed in the following tables (Frequency table and cross tabulation table). 
Table 1. Characteristics of Respondents

\begin{tabular}{|c|c|c|}
\hline Characteristic & Frequency (n) & Percentage (\%) \\
\hline \multicolumn{3}{|l|}{ Age } \\
\hline - $<20$ & 2 & 3.57 \\
\hline - $20-35$ & 50 & 89.29 \\
\hline - $>35$ & 4 & 7.14 \\
\hline \multicolumn{3}{|l|}{ Education } \\
\hline - Junior High School & 4 & 7.14 \\
\hline - Secondary High School & 22 & 39.29 \\
\hline - University & 30 & 53.57 \\
\hline \multicolumn{3}{|l|}{ Occupation } \\
\hline - Housewife & 34 & 60.71 \\
\hline - Entrepreneur & 18 & 32.14 \\
\hline - Civil Servant & 4 & 7.14 \\
\hline \multicolumn{3}{|l|}{ Parity } \\
\hline - 1 & 32 & 57.14 \\
\hline - 2 & 24 & 42.86 \\
\hline \multicolumn{3}{|l|}{ Type of Birth } \\
\hline Normal (vaginal birth) & 54 & 96.43 \\
\hline Caesarean & 2 & 3.57 \\
\hline \multicolumn{3}{|l|}{ Breastfeeding } \\
\hline Exclusive & 44 & 78.57 \\
\hline Non-Exclusive & 12 & 21.43 \\
\hline \multicolumn{3}{|l|}{ Blood Volume } \\
\hline - $\quad<500$ & 54 & 96.43 \\
\hline - $>500$ & 2 & 3.57 \\
\hline \multicolumn{3}{|l|}{ Duration of vaginal bleeding } \\
\hline - $\quad<14$ days & 44 & 78.57 \\
\hline - $>14$ days & 12 & 21.43 \\
\hline
\end{tabular}

Table 2. Exclusive Breastfeeding and Blood Volume

\begin{tabular}{|c|c|c|c|c|c|c|c|}
\hline \multirow{3}{*}{ Exclusive Breastfeeding } & \multicolumn{4}{|c|}{ Blood Volume(ml) } & \multicolumn{2}{|c|}{ Total } & \multirow{3}{*}{ P-Value } \\
\hline & \multicolumn{2}{|c|}{$<500$} & \multicolumn{2}{|c|}{$>500$} & \multirow{2}{*}{$\mathbf{n}$} & \multirow{2}{*}{$\%$} & \\
\hline & n & $\%$ & $\mathbf{n}$ & $\%$ & & & \\
\hline Yes & 44 & 100 & 0 & 0,0 & 44 & 100 & \multirow{2}{*}{0.06} \\
\hline No & 10 & 83.3 & 2 & 16.7 & 12 & 100 & \\
\hline
\end{tabular}

Table 3. Exclusive Breastfeeding and Blood Duration

\begin{tabular}{|c|c|c|c|c|c|c|c|}
\hline \multirow{3}{*}{$\begin{array}{l}\text { Exclusive } \\
\text { Breastfeeding }\end{array}$} & \multicolumn{4}{|c|}{ Bleeding Duration } & \multicolumn{2}{|c|}{ Total } & \multirow{3}{*}{ P-Value } \\
\hline & \multicolumn{2}{|c|}{$<14$} & \multicolumn{2}{|c|}{$>14$} & \multirow{2}{*}{$\mathbf{n}$} & \multirow{2}{*}{$\%$} & \\
\hline & $\mathbf{n}$ & $\%$ & $\mathbf{n}$ & $\%$ & & & \\
\hline Yes & 43 & 97.7 & 1 & 2.3 & 44 & 100 & \multirow{2}{*}{0.00} \\
\hline No & 1 & 8.3 & 11 & 91.7 & 12 & 100 & \\
\hline
\end{tabular}




\section{Discussion}

Exclusive Breastfeeding and Blood Volume: Breastfeeding is the most effective way to ensure the health and survival of both infants and mother. WHO recommended providing exclusive breastfeeding (6 months) for a child without giving any formula milk and any food. In this research, exclusive breastfeeding was defined as an activity breastfeeding of respondents who gave breast milk only to their baby at least for 1 month. The result of this study revealed thatall the respondents who breastfed exclusivelyhad blood volume $<500 \mathrm{ml}$. However, the data showed that the percentage of the mother who did not provide exclusive breastfeeding and had blood volume $<500 \mathrm{ml}$ is high as well. The result of this study suggested that there was no association between exclusive breastfeeding and blood volume.

World Health Organization (WHO) and The United Nation Children's Fund (UNICEF) recommends early initiation of breastfeeding within one hour of birth to stimulate breast milk production. It also stimulates uterine activity which can reduce the risk of heavy bleeding and infection ${ }^{9,10}$. Maternal death in the postpartum period can be caused by the amount of blood (volume) that comes out after delivery. The simple and easy strategy to reduce the Maternal Mortality Rate (MMR) and Infant Mortality rate (IMR) is breastfeeding directly (early initiation) and breastfeed exclusively to baby because breast milk contains Immunoglobulin which can prevent infection and diarrhoea.

Nipple stimulation, either manually using a breast pump or by encouraging the baby to suckle is a method to reduce bleeding after birth. It can be used immediately after childbirth to increase the secretion of the hormone called "oxytocin". Thereby, if the mother breastfeeds the baby immediately after giving birth, postpartum bleeding can be prevented or blood volume will be lower. When oxytocin is released or the level increase, it causes uterus contraction and helps the uterus back to the normal size which can lead to the reduction of postpartum bleeding ${ }^{3,11}$. Early initiation and the breastfeeding frequency immediately after birth will reduce the amount of vaginal blood loss and improve uterine involution ${ }^{12}$.

Some studies found that breastfeeding related to postpartum haemorrhage. A retrospective cohort study which analysed birth cohort $(n=3671)$ and conducted in New South Wales (NSW) Australia (2015) showed that breastfeeding and skin-to-skin contact immediately after giving birth may be effective in reducing $\mathrm{PPH}$ for women at any level of risk of $\mathrm{PPH}^{13}$. A quasiexperimental study $(\mathrm{n}=50)$ conducted in Alexandria, Egypt (2004) revealed that early breastfeeding had a statistically significant effect $(\mathrm{p}=0.001)$ on post-birth blood loss. The early breastfeeding group of women lost less than $150 \mathrm{ml}$ of blood; the later breastfeeding group lost $300 \mathrm{ml}$ or more. A study which was carried out in Tegal regency, Indonesia (2015) showed that there was a relationship between early breastfeeding and postpartum haemorrhage.

However, this study, conducted in Kassi-Kassi PHC, Makassar city of Indonesia, showed a different result with the previous studies that stated breastfeeding influences vaginal bleeding after birth. This study suggested that exclusive breastfeeding was not related to blood volume after birth. the results showed that although all women who breastfed exclusively had blood volume $<500 \mathrm{ml}$, the percentage of women who did not breastfeed exclusively and had blood volume $<500 \mathrm{ml}$ is high as well $(83,3 \%)$. This result could be explained that exclusive breastfeeding is not the only one strategy to prevent blood volume loss $>500 \mathrm{ml}$ or postpartum haemorrhage, but at least breastfeeding and skin to skin contact immediately after childbirth should be encouraged to stimulate and release oxytocin hormone that helps to reduce vaginal bleeding. The result of this study is similar to systematic review found that there is not a significant difference between nipple stimulation (breastfeeding) versus no treatment concerning the incidence of PPH $(>500 \mathrm{ml})$ and blood loss in the third stage of labour ${ }^{3}$.

Although this study revealed that there was no association between exclusive breastfeeding and blood volume, exclusive breastfeeding has many benefits both infant and mother. It is not only can prevent haemorrhage but also prevent complication in a postpartum period. Thereby, it could reduce maternal morbidity and mortality after birth.

\section{Exclusive Breastfeeding and Duration of Vaginal}

Bleeding: Duration of vaginal bleeding in this study is how long the bleeding occurs in a postpartum period, whether less than 14 days or more than 14 days. The result showed that the percentage of women who breastfeed exclusively and had bleeding duration $<14$ days is very high and proportion of mother who did not provide exclusive breastfeeding and had bleeding duration $>14$ days is very high as well. The results of 
this study revealed that exclusive breastfeeding is related to the duration of vaginal bleeding.

In the process of lochia discharge, there are stages which require certain period of time. The time needed release lochia depends on the smoothness of the discharge, if the lochia discharge smoothly, the time required will be faster, that is $\leq 14$ days and conversely, if the lochia is not smooth, the time required will also be longer that is $>14$ days $^{14}$. This study is supported by research '(2016) which stated that mothers who experience stress during pregnancy and childbirth can cause breastfeeding problems whether breastmilk release or not. The hormones responsible for the lactation process are prolactin and oxytocin. Women who are being stress will affect the release of the hormone from neurohypophysis that leads to a blocking of the let-down reflex when the baby is being breastfed. These hormones have a role in stimulating the process of uterine contractions that influence lochia discharge.

A study in Indonesia (2011) shows, of the 30 respondents who breastfeed their baby (early initiation), there were 25 respondents (83.3\%) who had high normal uterine fundus. A decrease in the normal uterine fundal occurs because blood (lochia) which release after birth lasting $<14$ days $^{15}$. Conceptually the dominant factor influencing the return of menstruation or bleeding after childbirth is a hormonal regulation factor. The hormone that has an important role in bleeding begins with the release of the prolactin. This hormone is secreted by the anterior pituitary gland due to the stimulation of baby suction when suckling in the mammary areola area. Suction stimulation will be continued to the spinal cord through sensory nerve impulses and passed on to the brain, namely to the hypothalamus. In the next process, the hypothalamus will give a command to the posterior and anterior pituitary glands. The posterior pituitary gland secretes the hormone oxytocin which is useful for smoothing out breast milk. If the production of the hormone prolactin and the hormone oxytocin continues smoothly, it affects the uterus and ovaries. This effect is related to the smoothness of breast milk discharge needed by the baby at any time. Continuous suction in the mammary areola area gives a positive effect of myoepithelial cell contractions so that breast milk is quickly excreted. It will also have an impact on the uterus so that no bleeding and duration of bleeding will be shorter ${ }^{16}$.
The let-down reflex coincides with the production of prolactin by the anterior pituitary, stimulation originating from the baby's sucking is continued to the posterior pituitary (neurohypophysis) which is then excreted oxytocin. Through the bloodstream, this hormone goes to the uterus, causing contractions. The contraction of the squeezing milk breast that has been made, out of the alveoli and into the duct system and then flows through the ductus lactiferous into the baby's mouth ${ }^{17}$.

Neurohypophysis periodically secretes oxytocin (pulsatile). This process stimulates milk secretion from breastfeeding by causing contraction of myoepithelial cells in the alveoli and small milk ducts. Ejection or breast milk discharge is a reflex that is initiated by the suction of the nipple which stimulates neurohypophysis to release oxytocin. Breastfeeding also speeds up uterine involution because repeated stimulation of the nipple will release oxytocin which causes contraction of the uterine muscle ${ }^{18}$.

WHO recommends providing exclusive breastfeeding forbabiesuntil 6 months. Providing exclusive breastfeeding to infants will increase uterine involution thereby reducing postpartum complications. Breastfeeding also has a positive impact on the mother because the baby's sucking will cause uterine contractions that prevent post-partum bleeding. During breastfeeding, oxytocin releases after childbirth also reduce uterine bleeding and prevent about one-fifth of neonatal deaths. Therefore, a health provider should provide nutrition and lactation counselling for women during pregnancy and after childbirth ${ }^{19}$.

\section{Conclusion}

This study found out that all of the women who breastfed exclusively had blood volume loss $<500 \mathrm{ml}$, but the percentage women who did not breastfeed exclusively and had blood volume loss $<500 \mathrm{ml}$ is high as well. Thereby, this study suggested that there was no association between exclusive breastfeeding and blood volume loss. Meanwhile, exclusive breastfeeding related to the duration of vaginal bleeding after birth.

Conflict of Interest: No conflict interest regarding this study

Source of F unding: Muslim University of Indonesia

Ethical Clearance: Muslim University of Indonesia 


\section{References}

1. Bhushan DR. Breastfeeding Practices in Slums of Delhi, India: A Cross-Sectional Study. J Med Sci Clin Res. 2019;7(9):72-79. doi:10.18535/jmscr/ v7i9.12

2. Roesli. Initiation of Early Breastfeeding Plus Exclusive Breastfeeding. Jakarta: Pustaka Bunda; 2008.

3. Abedi P, Jahanfar S, Namvar F. Nipple stimulation or breastfeeding for preventing postpartum haemorrhage in the third stage of labour. Cochrane Database Syst Rev. 2013;2013(11). doi:10.1002/14651858.CD010845

4. Say L, Chou D, Gemmill A, et al. Global causes of maternal death: a WHO systematic analysis. Lancet Glob Heal. 2014;2(6):e323-e333.

5. Organization WH. Trends in maternal mortality: 1990 to 2013: estimates by WHO, UNICEF, UNFPA, The World Bank and the United Nations Population Division. 2014.

6. Tauho KD, Karwur FF. AN INSIGHT INTO MATERNAL DEATH CAUSED BY POSTPARTUM HEMORRHAGE IN WESTERN TIMOR, INDONESIA. J Keperawatan Indones. 2019;22(1):1-10.

7. Dept. of Reproductive Health and Research W. WHO Recommendations for the Prevention and Treatment of Postpartum Haemorrhage.; 2012.

8. Carroli G, Cuesta C, Abalos E, Gulmezoglu AM. Epidemiology of postpartum haemorrhage: a systematic review. Best Pract Res Clin Obstet Gynaecol. 2008;22(6):999-1012. doi:10.1016/j. bpobgyn.2008.08.004

9. Sharp K. Book Review: Evidence for the Ten Steps to Successful Breastfeeding. J Hum Lact. 1999;15(1):69-70. doi: $10.1177 / 089033449901500122$

10. UNICEF. Facts for Life. 3rd Edn United Nations Children's Fund: New York.; 2002.

11. Health $M$ of. Practicum of Midwifery Clinic II. First. Jakarta: PPSDM; 2018.

12. Al Sabati SY, Mousa O. Effect of Early Initiation of Breastfeeding on the Uterine Consistency and the Amount of Vaginal Blood Loss during Early Postpartum Period. Nur Prim Care. 2019;3(3):1-6.

13. Saxton A, Fahy K, Rolfe M, Skinner V, Hastie C. Does skin-to-skin contact and breast feeding at birth affect the rate of primary postpartum haemorrhage: Results of a cohort study. Midwifery. 2015;31(11):1110-1117. doi:10.1016/j. midw.2015.07.008

14. Wulandari H. Postpartum Midwifery Care. Yogyakarta: Gosyen; 2011.

15. Prawirohardjo S. Midwifery Science. Jakarta: YBPP; 2016.

16. Varney H. Midwifery (Textbook). Second Edi. Jakarta: EGC; 2007.

17. Martini. Association between Early Initiation and Uterine Fundal Height Martini of Postpartum Women on 7th Days in Kota Bumi PHC North Lampung, FKM UI. 2012.

18. Sherwood. Human Physiology from Cell to System. In: Jakarta: EGC; 2012.

19. Anggraini A. Application of Audio Visual Media to Improve Providing of Exclusive Breasfeeding Rate in North Bengkulu. Bunga Raflexia, Socal Serv J. 2018. 